\title{
Research on prevention and traceability management of COVID- 19 in cold chain logistics
}

\author{
Sicong $\mathrm{Li}^{1, *}$, Jing $\mathrm{Ye}^{1}$ \\ ${ }^{1}$ Research Institute of Highway Ministry of Transport, Beijing, China
}

\begin{abstract}
Though COVID-19 spreads, China's meat and other fresh food imports demand is still strong. The safety risk of imported fresh food carrying COVID-19 is increasing. Although China continues to improve the epidemic prevention and control and disinfection measures for imported fresh food, there are still many risk points for the spread of COVID-19 in the whole process of cold chain logistics. Through the construction of transportation monitoring platform, strengthening the collaborative management and control of management departments, optimizing the operation mode of imported food cold chain, improving the level of information intelligence, strengthening policy support and publicity guidance, accelerating the cultivation of leading enterprises and other measures, we can further strengthen the epidemic prevention and control and traceability management of China's cold chain logistics, and ensure the safety of fresh food circulation.
\end{abstract}

\section{INTRODUCTION}

With the normalization of epidemic prevention and control, China has entered a post epidemic era of longterm coexistence with COVID-19. Global COVID-19 continues to spread, and import pressure from outside China is increasing. The risk of imported cold chain food carrying COVID-19 is increasing. In Beijing, Qingdao, Tianjin, Dalian and other places, there was a cluster epidemic related to imported cold chain food. Although the virus prevention and control and disinfection measures of imported fresh food are constantly improved, there are many hidden dangers in the whole process of cold chain logistics of imported food from port, storage, transportation, distribution to sales.

\section{IMPORT OF FRESH FOOD}

In recent years, the import scale of fresh food in China has been expanding, and the proportion of fresh agricultural products in the import of agricultural products has exceeded $1 / 5^{[1]}$. China's imported fresh food mainly includes livestock products, aquatic products, fruits and vegetables, etc. Among them, domestic demand for livestock products and aquatic products is strong, and the import and export trade deficit is obvious ${ }^{[2]}$. Affected by African swine fever, the production capacity of China's pig industry declined seriously, and the gap between supply and demand of meat market increased ${ }^{[3]}$. In 2020, although COVID-19 was serious abroad, the import of meat in China continued to rise despite strong demand. In 2020, China's meat imports will reach 9.9 million tons, an increase of 3.72 million tons over 2019, with an increase of $60 \%$. Among them, the import volume of pork in 2020 will reach 4.38 million tons, an increase of $119 \%$ compared with that in 2019, effectively alleviating the shortage of domestic pork supply. In 2020, COVID-19 was detected in imported seafood packaging in many places of China, which has a huge impact on the supply chain of imported aquatic products. In 2020, China's import volume of aquatic and marine products will be 4 million tons, $10 \%$ lower than that in 2019; the import volume of aquatic and marine products will reach 89.68 billion yuan, $18 \%$ lower than that in 2019 .

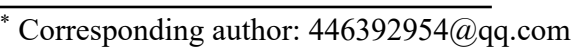




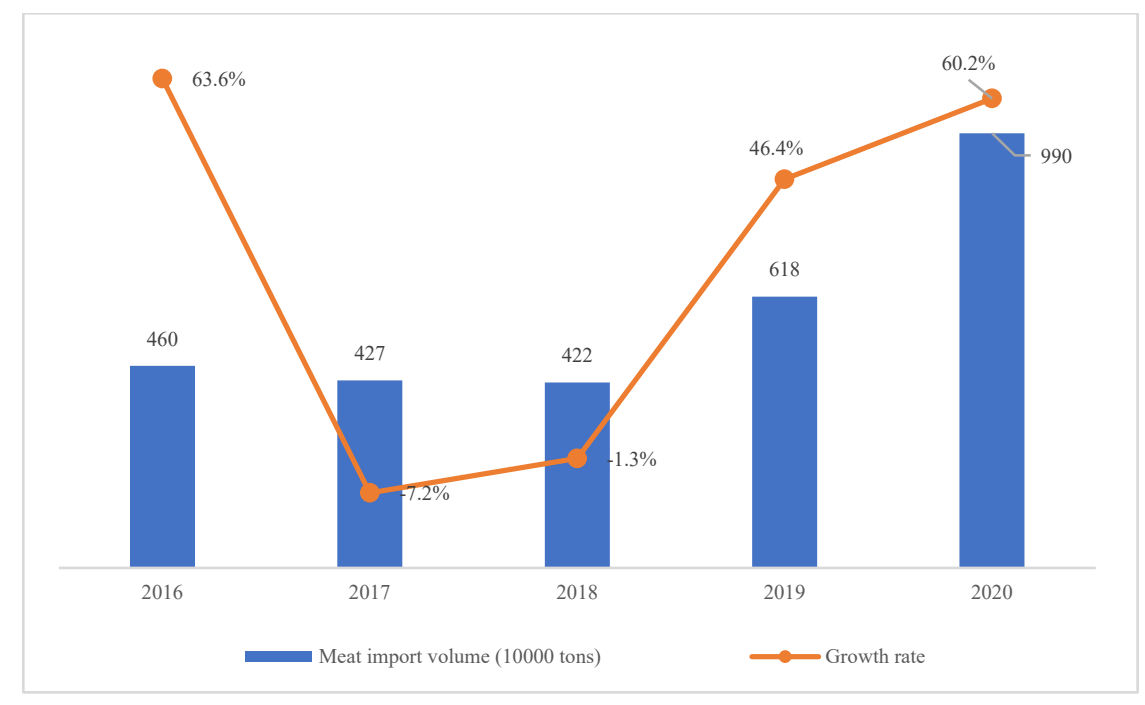

Fig.1. China's meat import volume and growth rate from 2016 to 2020

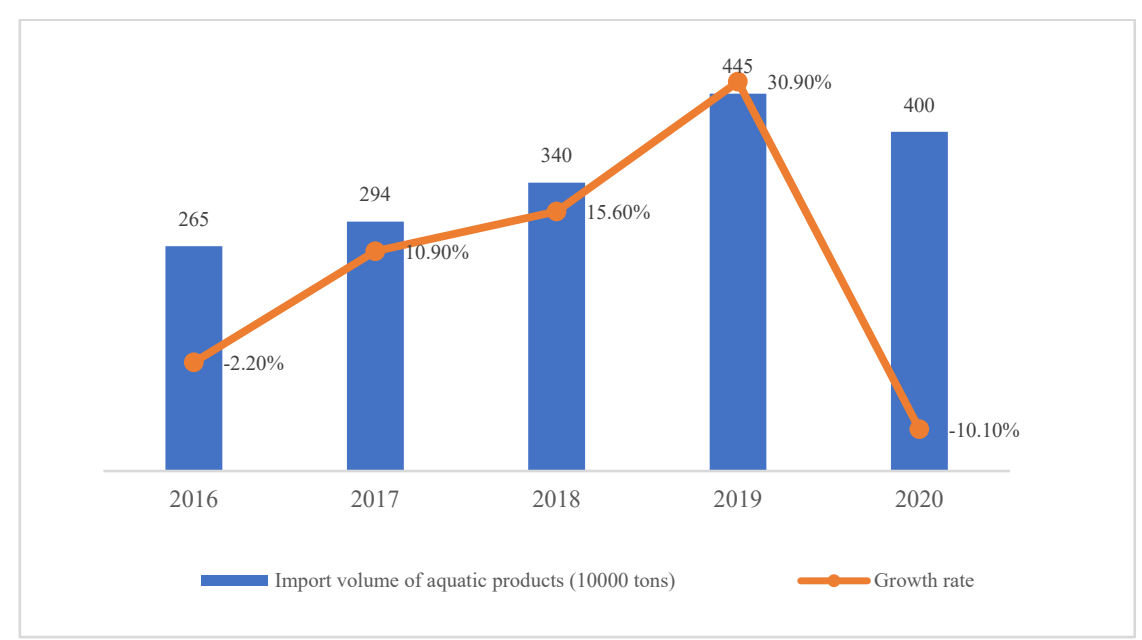

Fig.2. China's import volume and growth rate of aquatic and marine products from 2016 to 2020

\section{MAIN RISK POINTS}

\subsection{Main risks of port links}

At present, the Chinese customs has implemented the nucleic acid detection of COVID-19 in imported fresh food samples. In addition, China Customs will organize food importers and customs inspection sites to carry out preventive disinfection on the inner wall of imported fresh food containers and the outer packaging of goods. Sampling inspection and outer package disinfection have limitations. Even if the imported food has passed the sampling inspection and been thoroughly disinfected, there is still a risk that the products that have not been extracted will carry the COVID-19 into the domestic circulation.

\subsection{Main risks in warehousing}

At present, the storage enterprises require the cold storage operators to wear protective clothing, gloves, masks and other articles during the operation. However, in practical operation, protective clothing is easy to be damaged in the low temperature environment of cold storage, resulting in the exposure risk of operators. Due to the limitation of infrastructure, many warehouses are unable to store imported goods separately. There are hidden dangers of COVID-19 transmission in the mixed storage of imported cold chain food and domestic fresh goods.

\subsection{Main risks in transportation}

In winter, the temperature is cold and easy to freeze, so the cleaning and disinfection frequency of refrigerated vehicles is reduced. The commonly used alcohol and chlorine disinfectants have obvious odor, and some cargo owners require that the transport vehicles have no odor, otherwise they will reject the goods, which makes it difficult to implement the disinfection measures for some cold chain transport vehicles. The profit margin of China's cold chain transportation enterprises is very low. The needs of vehicle disinfection, regular detection and personnel protection raise the operating costs of enterprises, and the enterprises lack the enthusiasm to implement the requirements of epidemic prevention and control. 


\subsection{Main risks in distribution}

In the stage of urban distribution, domestic goods and imported goods are generally mixed transportation, which has the risk of virus transmission. In distribution vehicles, drivers can use alcohol disinfectant and paper towel for hand disinfection. However, there are many loading and unloading activities in urban distribution. Drivers usually wear gloves to load and unload goods, and take off gloves to sign to complete the handover, which has the risk of contact and communication.

\subsection{Main risks in sales}

In China, the development of the operation and management level of retailers is unbalanced, and the management of large chain supermarkets and e-commerce enterprises is relatively standardized. It is difficult to verify the purchase channels of small and medium-sized retailers, and there are potential safety hazards. It is difficult to separate domestic fresh goods and imported goods, and fresh food will be unpacked and sold in the smallest unit, so it is difficult to disinfect the food in the sales process. Many supermarkets and markets in China have detected positive cases of COVID-19 nucleic acid. Finally, with the improvement of domestic epidemic situation, some consumers relax their vigilance and no longer pay attention to personal protection, which is easy to cause infection.

\section{COUNTERMEASURES FOR EPIDEMIC PREVENTION AND AND TRACEABILITY MANAGEMENT}

\subsection{Construction of cold chain transportation monitoring platform}

Recently, the market supervision and administration departments in Beijing, Shanghai, Zhejiang, Fujian, Guangdong and other places have built the traceability platform of imported cold chain food to strengthen the traceability and prevention and control management of circulation links. At present, the imported cold chain food lacks the traceability of transportation links, so it is necessary to strengthen the traceability management of cold chain transportation vehicles. The road cold chain transportation monitoring platform should be built to carry out process monitoring and information traceability for refrigerated vehicles. The platform can be used to upload electronic waybill and real-time dynamic data such as vehicle temperature, track, etc., and connect with the systems of the General Administration of market supervision and customs to build an import cold chain food circulation traceability system through information sharing ${ }^{[4]}$.

\subsection{Strengthen the cooperation of industry management departments}

In order to reduce the risk of COVID-19 inflow, we should strengthen the sampling inspection of customs, strengthen the environmental monitoring and comprehensive disinfection of cargo storage at ports and airports. We should carry out spot check on the implementation of epidemic prevention and control measures in cold chain logistics enterprises, and regularly carry out environmental monitoring on transport vehicles and warehouses. When COVID-19 patients or nucleic acid monitoring positive environment are found in cold chain logistics enterprises, preventive measures such as emergency sealing control, emergency investigation and large-scale nucleic acid detection should be taken in time.

\subsection{Promote the "two centralized, four fixed" management mode of cold chain logistics}

The operators and working areas of imported fresh food should be concentrated. In many areas of China, supervision warehouses for imported fresh food have been set up, with fixed operators, fixed operation sites, fixed production equipment and fixed rest areas. The list of import cold chain transportation enterprises should be set up, and the transportation enterprises, drivers, vehicles and parking areas should be fixed from the port to the centralized supervision warehouse.

\subsection{Using information technology to complete "contactless" operation}

Mechanized and automatic equipment should be used instead of manual operation. We should promote standardized pallets and develop automatic cold storage, so as to reduce manual operation and infection risk of operators. In the process of transportation, the application of electronic lead seal can prevent the driver or entourage from opening the box without permission and block the risk of infection. To promote "paperless, contactless" handover, upstream and downstream enterprises can use the information system to realize business connection and data transmission, and use mobile app or terminal equipment to carry out electronic signature in the receiving and shipping links, so as to reduce personnel contact in all links and reduce the risk of virus transmission.

\subsection{Strengthen the policy guarantee of epidemic prevention and control in cold chain enterprises}

Provide financial support for epidemic prevention and control for cold chain logistics enterprises serving people's livelihood and medical materials, and use it for nucleic acid detection costs of personnel, goods and environment, as well as protection material purchase and vaccination. In addition, we should ensure that the cold chain logistics transportation, loading and unloading operators give priority to vaccinating the COVID-19 vaccine to reduce the possibility of virus infection. 


\subsection{Strengthen the awareness of epidemic prevention and control and food safety of consumers}

We should strengthen publicity, improve consumers' awareness of epidemic prevention and control, and do a good job in personal protection and disinfection. Further strengthen consumers' attention to cold chain logistics and goods traceability, so as to strengthen the supervision of the whole society on the cold chain logistics industry and promote the healthy development of the industry.

\subsection{Speed up the cultivation of leading cold chain logistics enterprises}

The development of China's cold chain logistics enterprises is uneven, and the market concentration is low $^{[5]}$. Jingdong Logistics, Shunfeng logistics and other large enterprises have strong supply chain management, network operation, platform service strength, and can actively do a good job in preventive disinfection and goods traceability management. We can carry out pilot demonstration work, speed up the cultivation of leading enterprises and promote the intensive development of cold chain logistics by carrying out enterprise credit evaluation and classified management ${ }^{[6]}$.

\section{CONCLUSION}

COVID-19 exposes many problems of the cold chain industry, and also brings the cold chain logistics industry a new development opportunity. In view of the main risk points of virus transmission in the circulation of imported fresh food, this paper puts forward some countermeasures, such as establishing transportation monitoring platform, optimizing logistics operation mode, promoting "contactless" operation, cultivating large leading enterprises, strengthening policy guarantee and consumer awareness. These countermeasures can not only help to strengthen the epidemic prevention and traceability management of cold chain logistics, but also have great significance to accelerate the healthy development of cold chain logistics industry.

\section{ACKNOWLEDGEMENT}

This paper is funded by the Special Funds Project for Basic Scientific Research Business Expenses of the Central Public Welfare Research Institute (2020-9017).

\section{REFERENCE:}

1. L. Yuan, B. Wang. Causes for the Growth of China's Imported Fresh Agricultural Products and the Trends of That. China Business And Market (Vol.31, No.12) :56-64(2017)

2. X. Xu. Import trade of fresh agricultural products in China: characteristics, influencing factors and Prospects. Practice In Foreign Economic Relations And Trade. 09-013:48_51 (2018)
3. X.Chen, W.Liu, S Wang. Analysis on the factors of promoting the import trade of fresh agricultural products in China. Tianjin agriculture and forestry science and technology. No 6:8-12 (2020)

4. Y. Sheng, A Zhou, J Li. Discussion on the construction of agricultural products cold chain logistics public information platform -- Based on the Internet of things. Modern Business Trade Industry. No,02: 12-13 (2013)

5. J.YE, S. Li, Problems and Measures of Agricultural Products Cold Chain Logistics Development in the Rural Vitalization Strategy. China Transportation Review. Vol 41, No.12:102-105(2019)

6. S. Li, J.Ye, R.Li. Management and practical experience of cold chain logistics industry in Germany and Its Enlightenment to China. China Transportation Review. Vol 41, No.12:108113(2020) 